\title{
A quick and efficient hydroponic potato infection method for evaluating potato resistance and Ralstonia solanacearum virulence
}

\author{
Huijuan Wang ${ }^{1 \dagger}$, Jinxue Hu${ }^{1 \dagger}$, Yao Lu ${ }^{1 \dagger}$, Mancang Zhang ${ }^{1 \dagger}$, Ning Qin' ${ }^{1}$, Ruize Zhang ${ }^{1}$, Yizhe He ${ }^{1}$, \\ Dongdong Wang ${ }^{1}$, Yue Chen', Cuizhu Zhao', Núria S. Coll², Marc Valls ${ }^{2,3}$, Qin Chen ${ }^{4^{*}}$ and Haibin Lu ${ }^{1 *}$ (D)
}

\begin{abstract}
Background: Potato, the third most important crop worldwide, plays a critical role in human food security. Brown rot, one of the most destructive potato diseases caused by Ralstonia solanacearum, results in huge economic losses every year. A quick, stable, low cost and high throughout method is required to meet the demands of identification of germplasm resistance to bacterial wilt in potato breeding programs.

Results: Here we present a novel R. solanacearum hydroponic infection assay on potato plants grown in vitro. Through testing wilt symptom appearance and bacterial colonization in aerial part of plants, we found that the optimum conditions for in vitro potato infection were using an $\mathrm{OD}_{600} 0.01$ bacterial solution suspended with tap water for infection, broken potato roots and an open container. Infection using $R$. solanacearum strains with differential degree of aggressivity demonstrated that this infection system is equally efficient as soil-drench inoculation for assessment of $R$. solanacearum virulence on potato. A small-scale assessment of 32 potato germplasms identified three varieties highly resistant to the pathogen, which indicates this infection system is a useful method for high-throughout screening of potato germplasm for resistance. Furthermore, we demonstrate the utility of a strain carrying luminescence to easily quantify bacterial colonization and the detection of latent infections in hydroponic conditions, which can be efficiently used in potato breeding programs.
\end{abstract}

Conclusions: We have established a quick and efficient in vitro potato infection system, which may facilitate breeding for new potato cultivars with high resistance to $R$. solanacearum.

Keywords: Ralstonia solanacearum, Potato, In vitro infection, Brown rot, Bacterial wilt

\section{Background}

Ralstonia solanacearum is the causal agent of bacterial wilt (also known as brown rot on potato), one of the most destructive plant diseases on many crops in tropical and subtropical areas, which leads to huge losses in food

\footnotetext{
*Correspondence: chenpeter2289@nwsuaf.edu.cn; luhaibin011@hotmail. com

${ }^{\dagger}$ Huijuan Wang, Jinxue Hu, Yao Lu and Mancang Zhang contributed equally to this work

${ }^{1}$ College of Agronomy and State Key Laboratory of Crop Stress Biology for Arid Areas, Northwest A\&F University, Yangling 712100, Shaanxi, China

${ }^{4}$ State Key Laboratory of Crop Stress Biology for Arid Areas, College of Food Science and Engineering, Northwest A \& F University,

Yangling 712100, Shaanxi, China

Full list of author information is available at the end of the article
}

production [1]. This soil-borne bacterium enters root through wounds or natural openings and multiplies in the vascular tissues, which results in xylem dysfunction and ultimately kills the plant host [2,3]. The bacterium is also able to survive for years in soil and water retaining the ability to invade host plants [4].

$R$. solanacearum is a heterogeneous species composed of many genetic groups referred to as the R. solanacearum species complex (RSSC) [2, 3]. Phylogenetic analyses of several conserved genes revealed that the RSSC is divided into four phylotypes: phylotype I isolates are mainly from Asia, phylotypes II and III are, respectively, composed of American and African strains and

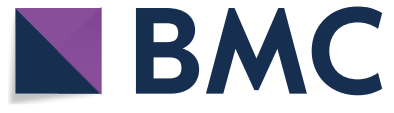

(c) The Author(s) 2019. This article is distributed under the terms of the Creative Commons Attribution 4.0 International License (http://creativecommons.org/licenses/by/4.0/), which permits unrestricted use, distribution, and reproduction in any medium, provided you give appropriate credit to the original author(s) and the source, provide a link to the Creative Commons license, and indicate if changes were made. The Creative Commons Public Domain Dedication waiver (http://creativecommons.org/ publicdomain/zero/1.0/) applies to the data made available in this article, unless otherwise stated. 
phylotype IV strains originate from Indonesia, Japan, Australia and the Philippines $[5,6]$.

Besides its worldwide geographic distribution, $R$. solanacearum possesses an extraordinarily broad host range, causing disease on more than 200 plant species from 50 different botanical families [3]. The pathogen not only infects solanaceous crops such as tomato, eggplant, peanut, pepper and potato, but also other plants from both the dicot and monocot families, and new hosts are being discovered continuously [7]. Due to its wide geographical distribution, broad host range, long persistence in soil and highly aggressivity on plants, the bacterium was ranked by scholars as the second most important bacterial plant pathogen [1].

Potato is currently the third most important staple food crop for human direct consumption just after rice and wheat and it ranks first in energy and protein production per unit of water $[8,9]$. In protein produced per acre land, potato ranks second to soybean. Importantly, potato is rich in microelements and vitamins essential for the human diet, such as vitamin $C$, potassium and in fiber [8]. Brown rot caused by $R$. solanacearum is one of the most notorious potato diseases, estimated to result each year in 1 billion US\$ economic losses worldwide [1]. Breeding new potato cultivars with resistance to brown rot is essential for integrated management of this disease. To this end, the development of procedures to facilitate the screening for resistance in germplasm from wild potato collections, progenies from crosses between potato species and potato transgenic lines will help potato breeding programs.

Soil-drench and stem-puncture inoculation are the two methods most widely used to study plant resistance to $R$. solanacearum [10-13]. However, adult full-size plants are needed in these procedures with the ensuing use of space, energy and time. Furthermore, since $R$. solanacearum is a soil-borne root pathogen, stem penetration bypasses potential root resistance mechanisms. The disadvantage of soil-drench inoculation is that the opacity of soil hinders the direct investigation of root responses to the pathogen. Vass et al. inoculated tomato plants grown in hydroponic conditions to study $R$. solanacearum root colonization [14]. More recently, in vitro pathogenicity assays have been successfully established on tomato [15], Arabidopsis [16, 17], petunia [18] and M. truncatula [19]. However, miniaturized in vitro infection assays have not been set up to screen for resistance in potato to the pathogen. We previously generated constitutively luminescent $R$. solanacearum reporter strains, a tool that we have used to characterize the colonization and the defense responses of potato breeding lines [20, 21]. Here we have established a faster, highly efficient, low-cost potato hydroponic infection method to study
$R$. solanacearum-potato interactions. Using this new method, we successfully characterized the virulence of several $R$. solanacearum strains on potato and screened for potato varieties showing resistance to $R$. solanacearum. We also simplified the screening process using a luminescent pathogen that can be tracked in vivo in infected plants. This new method will promote the study of potato resistance to $R$. solanacearum and provide insights for investigating other root pathogens of potato under gnotobiotic conditions.

\section{Results}

Development of an in vitro potato infection system for $R$. solanacearum

Aiming at the quick identification of potato resistance to $R$. solanacearum, we designed a method for infection in vitro Fig. 1a). A $10^{7}-10^{8}$ colony forming units (cfu)/ $\mathrm{ml} R$. solanacearum suspension is used to infect plant hosts such as Arabidopsis, tomato and potato [13, 20, 22]. Thus, we grew potato plants hydroponically in MS liquid medium for two weeks, injured the roots and transferred them to the same medium containing $1 \times 10^{8} \mathrm{cfu} / \mathrm{ml}$ of $R$. solanacearum strain GMI1000, belonging to the phylotype I. The leaves of the infected plants started wilting at 4 days post inoculation (dpi). At $5 \mathrm{dpi}$, almost all plants exhibited severe wilting symptoms, while the leaves of plants mock-treated with water kept green and healthy (Fig. 1b). This suggested that in vitro infection could be employed to test the virulence of $R$. solanacearum in potato.

Wilt symptoms appear when water transport in the xylem is blocked by lipopolysaccharides produced by $R$. solanacearum [2]. We thus hypothesized that increased evapotranspiration by opening the growth container's lids could accelerate plant wilting. To test this possibility, plant inoculations were carried out in parallel under opened and closed lid conditions. Although the same number of wilted plants was observed in both conditions, plants in the open jars exhibited more severe wilting symptoms than those in the close jars (Fig. 2a). We further measured $R$. solanacearum growth in the aerial part of potato plants. The amount of bacteria in plants in the open and close jars was comparable (Fig. 2b), suggesting the air exchange does not affect bacterial growth, but enhances wilting. In nature, $R$. solanacearum enters root at the emergence sites of lateral roots or root tips [2]. To test whether this natural infection also worked in our in vitro infection system, 2-week-old plants without injury were directly infected with the $1 \times 10^{8} \mathrm{cfu} /$ $\mathrm{ml} R$. solanacearum solution. Even at $9 \mathrm{dpi}$, no potato plant exhibited wilting symptoms in these conditions (Fig. 3a). To confirm successful colonization in plants, we measured bacterial loads in the aerial plant tissues. 


\section{a}

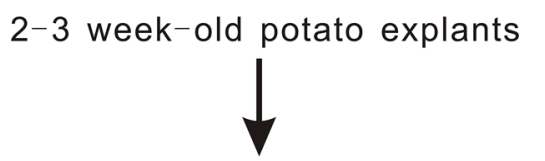

Cut $2 \mathrm{~cm}$ shoot, insert them into paper holder and grow for 2-3 weeks in liquid MS2 medium

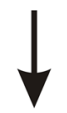

Cut root with scissors and transfer potato explants into $30 \mathrm{ml}$ R. solanacerum suspension solution

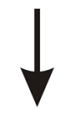

Observe and record leaf wilting symptom after 2-3 dpi and measure bacterial proliferation in the stem at 4-6 dpi
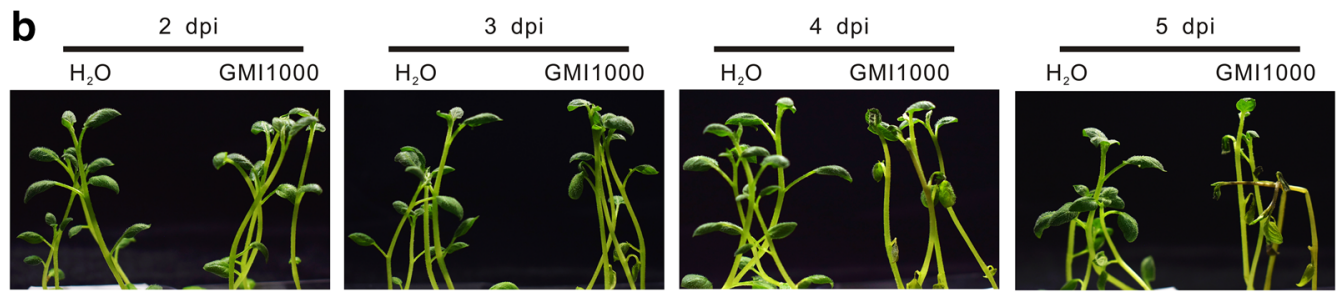

Fig. 1 R. solanacearum inoculation causes wilting of potato grown under hydroponic conditions. Roots of 2-week-old potato plants were cut and inoculated with $1 \times 10^{8} \mathrm{cfu} / \mathrm{ml}$ GMI1000. a Workflow of the in vitro potato infection method. b Representative digital images of bacterial wilt development taken at the indicated days post-infection (dpi). The experiment has been repeated more than three times with similar results

The amount of the pathogen in both conditions reached $10^{8} \mathrm{cfu} / \mathrm{g}$ at $9 \mathrm{dpi}$ (Fig. 3b), which is 10 -fold lower than the $10^{9} \mathrm{cfu} / \mathrm{g}$ attained in the root-cut plants at $5 \mathrm{dpi}$ (Fig. 2b). Therefore, plant inoculation without root injury resulted in symptomless infections due to lower bacterial numbers. Thus, the root-cutting treatment was selected for the following experiments based on its faster, reproducible infection, which correlated with the development of wilting symptoms.

The bacterial concentration $\left(1 \times 10^{8} \mathrm{cfu} / \mathrm{ml}\right)$ used in laboratory inoculations is usually far higher than that occurring in nature $[13,20,22]$. To check whether lower inocula could be used for in vitro potato infection, disease development in plants was investigated using a series of bacterial suspensions. Eighty percent of plants infected with the higher bacterial solution concentration $\left(1 \times 10^{8} \mathrm{cfu} / \mathrm{ml}\right.$ and $\left.1 \times 10^{7} \mathrm{cfu} / \mathrm{ml}\right)$ showed wilting symptoms at $8 \mathrm{dpi}$. At this time those plants infected with the lowest bacterial concentration $\left(1 \times 10^{6} \mathrm{cfu} /\right.$ $\mathrm{ml}$ ) just started wilting (Fig. 4a). Moreover, potato plants inoculated with $1 \times 10^{8}$ or $1 \times 10^{7} \mathrm{cfu} / \mathrm{ml}$ showed similar amounts of bacteria in the aerial part of plant, while those inoculated with the $1 \times 10^{6} \mathrm{cfu} / \mathrm{ml}$ solution contained fivefold less bacteria (Fig. 4b). This suggested that $1 \times 10^{7} \mathrm{cfu} / \mathrm{ml}$ is the optimum $R$. solanacearum concentration to inoculate potato plants in hydroponic conditions.

In the previous experiments, liquid MS medium containing many nutrients and vitamins (MS-) was used to re-suspend $R$. solanacearum for infection. To rule out a potential effect of the MS medium on $R$. solanacearum growth or virulence, we substituted the MS - medium with tap water. Wilting symptoms developed faster and stronger on potato plants in tap water containing $R$. solanacearum than in MS - medium with the same bacterial concentrations (Fig. 5a). In line with this observation, the amount of bacteria in potato plants treated with the water-resuspended pathogen was fivefold higher than in the potato plants treated with MS- resuspended bacteria (Fig. 5b).

\section{Hydroponic potato infection can be used to study $R$. solanacearum virulence in vitro}

HrpG and HrpB, two key regulators of the bacterial type three secretion system, play critical regulatory roles in $R$. solanacearum virulence. The hrpG and $h r p B$ 


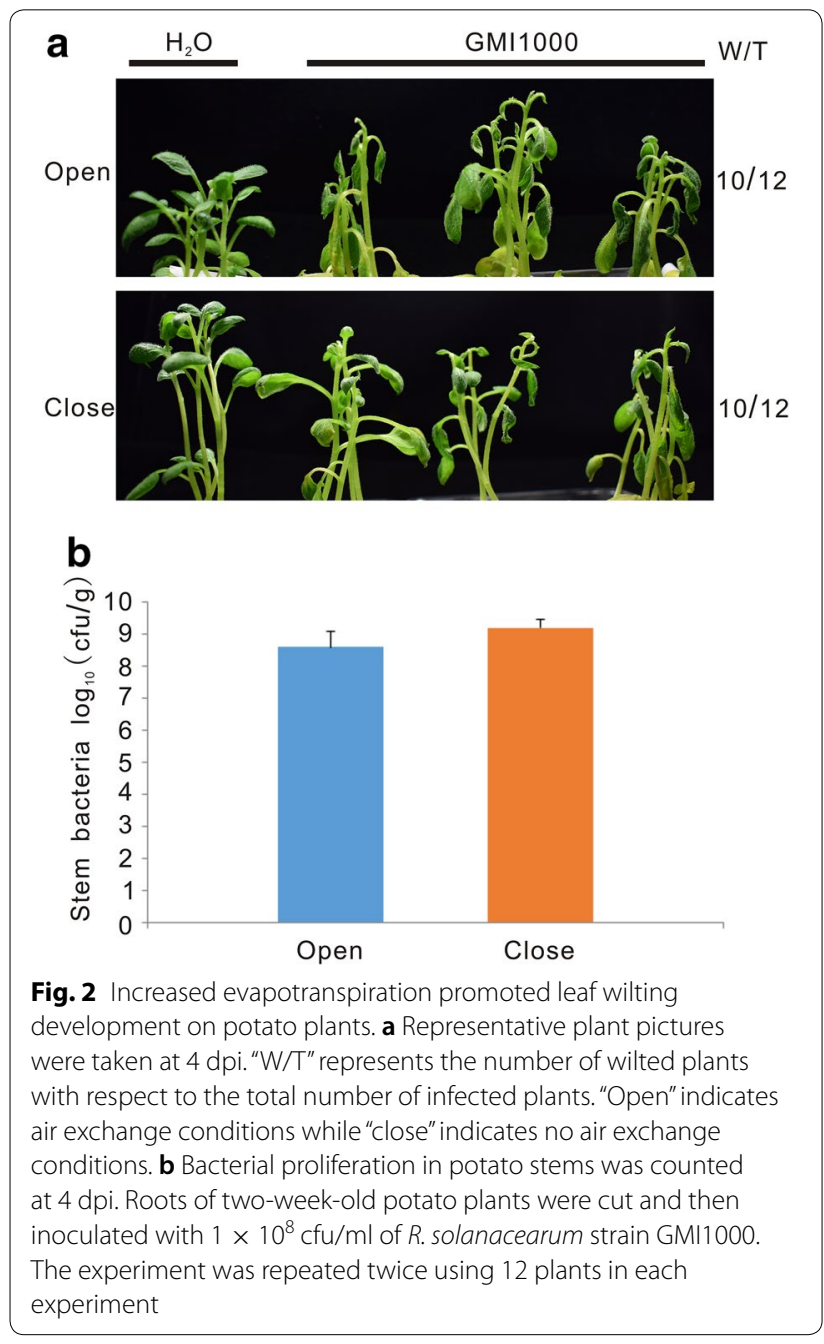

mutant strains lose the ability to invade tomato $[14,23$, $24]$. To determine whether our in vitro infection system was suitable to evaluate $R$. solanacearum pathogenesis, we first infected potato plants with $R$. solanacearum GMI1000 wild type (wt), and the same strain carrying a precise deletion of the $h r p G(\Delta h r p G)$ or the $h r p B$ coding sequence $(\triangle h r p B)$. The $h r p B$ and $h r p G$ mutants did not cause any bacterial wilt disease when compared with the strong wilting symptoms caused on potato plants by the wild type strain (Fig. 6a). Bacterial growth analysis showed that the potato colonization was similar in $h r p G$ and $h r p B$ mutants, but this bacterial content in stems was 100 fold lower than that of the wild type GMI1000 (Fig. 6b). These data indicate that mutations on $\operatorname{HrpB}$ and HrpG abolish R. solanacearum virulence on potato, which is consistent with the fact that both mutants are non-pathogenic on tomato and Arabidopsis [23, 25]. Next, we selected wild type $R$.

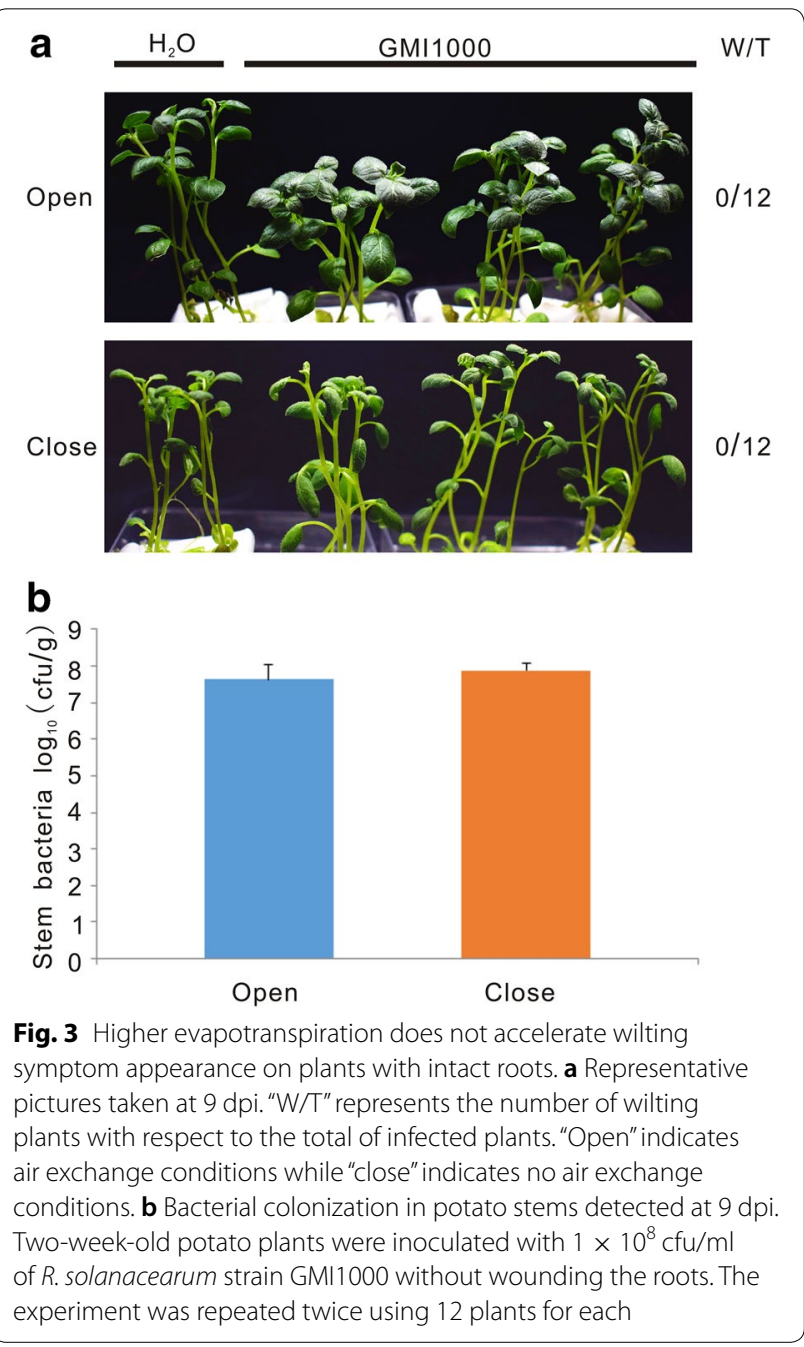

solanacearum strains different from GMI1000 to test their aggressivity in our hydroponic potato infection system. Brown rot of potato is most commonly caused in the field by a subgroup of $R$. solanacearum strains belonging to phylotype IIB [26]. UW551 and IPO1609 from this group and the related CFBP2957 and CIP301 strains from phylotype IIA, were selected to investigate their virulence [6]. UW551 and CFBP2957 infection resulted in a strong leaf wilt symptom while IPO1609 and CIP301 did not cause any visible symptom (Fig. 7a). In addition, the multiplication of UW551 and CFBP2957 in potato was 100 fold higher than that of IPO1609 and CIP301 (Fig. 7b). Our results indicate that UW551 and CFBP2957 are much more aggressive on potato than IPO1609 and CIP301. Hence the in vitro infection system we have established here can be used to measure differences in the aggressivity of $R$. solanacearum stains on potato. 


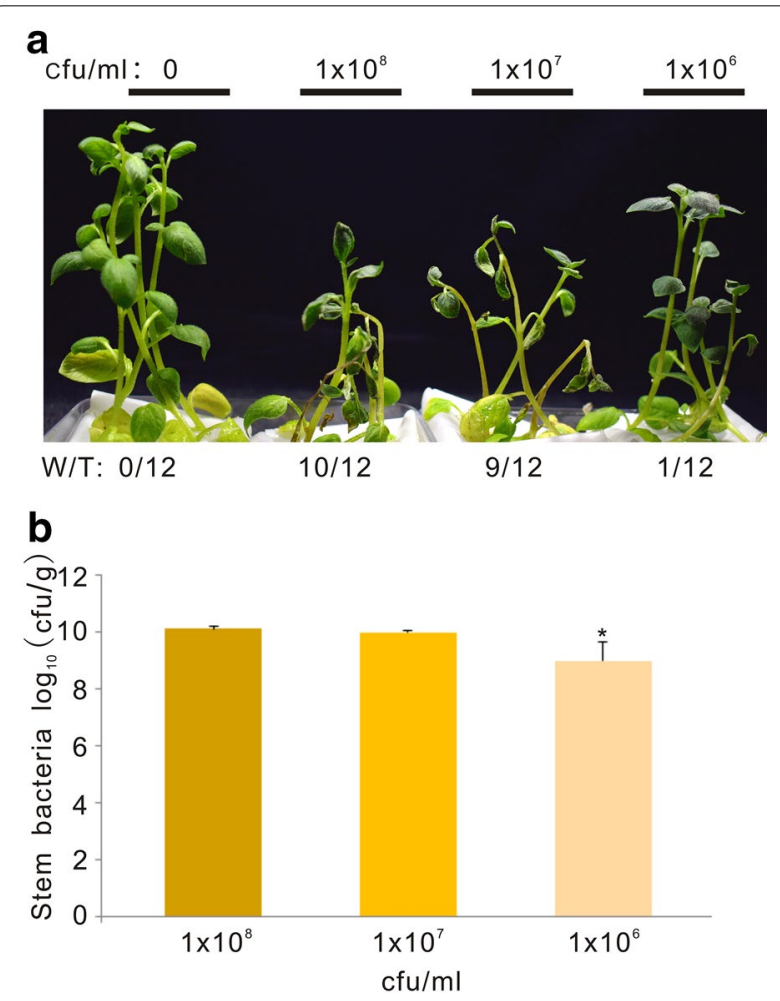

Fig. 4 Potato plants infected with different $R$. solanacearum concentrations. a Representative pictures taken at $8 \mathrm{dpi}$. "W/T" represents the number of wilting plants with respect to the total of infected plants. b Bacterial colonization in potato stems counted at $8 \mathrm{dpi}$. The root-cut potato plants were infected with different concentrations of bacterial solutions as indicated. Each experiment was repeated three times using 12 plants each with similar results. Asterisk indicates $P<0.01$ (Student's $t$ test) with respect to the $1 \times$ $10^{8} \mathrm{cfu} / \mathrm{ml}$ bacteria innocula

\section{Evaluation of the resistance of potato varieties to $R$. solanacearum}

Easy identification of potato varieties with high resistance to $R$. solanacearum is a prerequisite for potato breeding programs. Hence, we performed a small scale experiment to test if our pathosystem could be used to efficiently screen for potato resistance to $R$. solanacearum. Thirty-two varieties of Solanum tuberosum L. $S$. tuberosum subsp. andigenum, S. raphanifolium and $S$. pinnatisectum were grown and inoculated using our hydroponic conditions. The results obtained from six of these varieties and the control susceptible variety Desirée are shown in Fig. 8. Wilting symptoms were clearly abolished on varieties $\mathrm{O}$ and $\mathrm{P}$, and delayed on $\mathrm{B}, \mathrm{M}$ and $\mathrm{N}$ species, compared to variety $\mathrm{L}$ and the control susceptible variety Désirée (Fig. 8a). Consistent with this, the population of the pathogen in $\mathrm{O}$ and $\mathrm{P}$ was 1000 fold lower than that in Désirée, suggesting $\mathrm{O}$ and $\mathrm{P}$ are highly resistant to $R$. solanacearum (Fig. 8). Interestingly, the

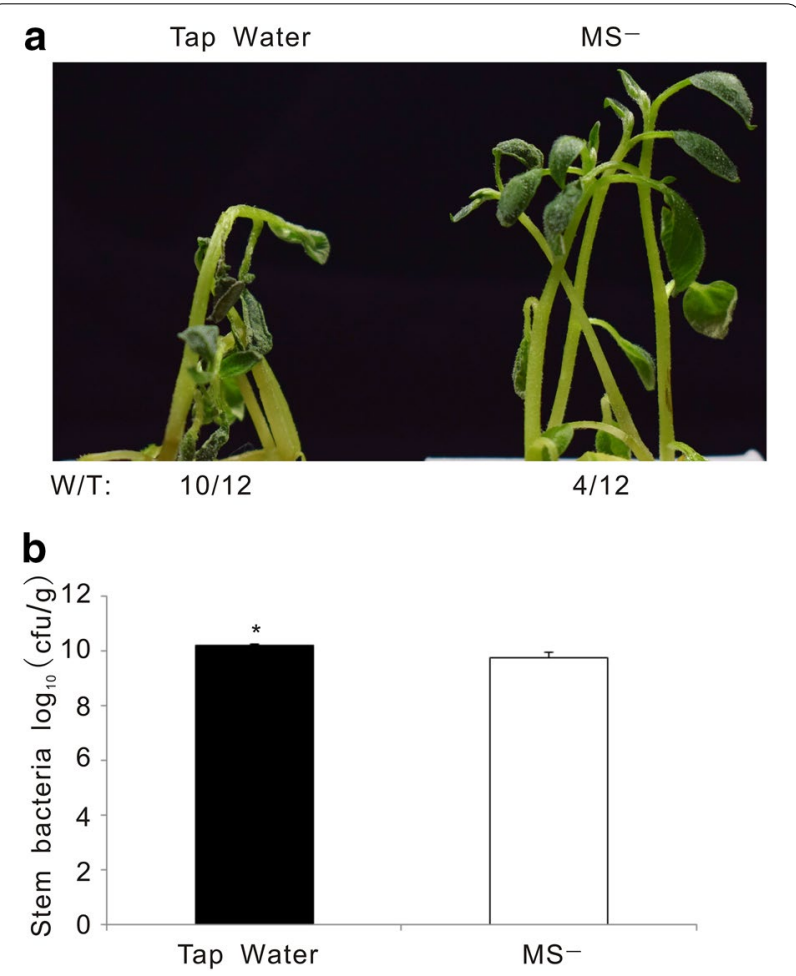

Fig. 5 Tap water-resuspended bacterial solutions triggered stronger bacterial wilt disease symptoms than MS-resuspended bacterial solutions. a Wilting symptoms in representative photographs at $4 \mathrm{dpi}$. "W/T" represents the number of wilting plants with respect to the total of infected plants. $\mathbf{b}$ Bacterial content in potato stem recorded at $4 \mathrm{dpi}$. This experiment was repeated three times with similar results. Student's $t$ test was performed with respect to MS- solution $(P<0.05)$

pathogen population in $\mathrm{M}$ was twofold lower than that in Désirée (Fig. 8b), but significantly delayed wilting symptom development, indicating that $\mathrm{M}$ is a tolerant potato variety towards strain GMI1000. Reactive oxygen species (ROS) play a key role in plant defense [27]. To ascertain whether ROS production was triggered in the resistance plants $\mathrm{O}$ and $\mathrm{P}$ in response to $R$. solanacearum, we measured it in leaves of $\mathrm{O}, \mathrm{P}$ and Desirée infiltrated with the pathogen. Comparing with Desirée and $\mathrm{O}$, higher ROS level was detected in P plants at 3 dpi (Fig. 8c). This suggests that ROS signaling may be part of the defense responses of $\mathrm{P}$ leading to resistance to $R$. solanacearum. Moreover, while the leaf-infiltrated Desirée plants exhibited wilting symptoms, $\mathrm{O}$ and $\mathrm{P}$ plants did not (Fig. 8c). This indicates that the resistance of $\mathrm{O}$ against $R$. solanacearum seems to be controlled by alternative, ROSindependent mechanisms.

The observation of symptomless plants does not always correlate with potato resistance to $R$. solanacearum as symptomless latent infections often occur [20]. Thus, bacterial counts must be also assayed. However, 


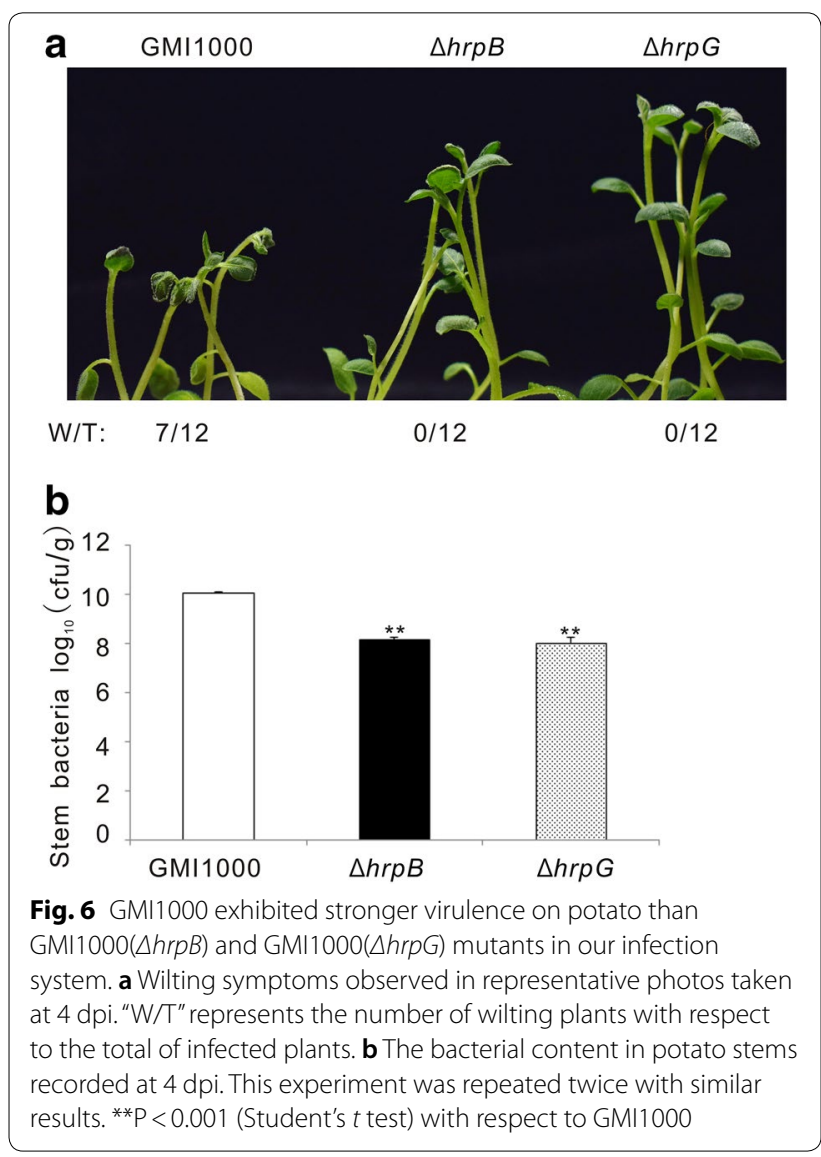

measuring bacteria in plants is a laborious task that cannot be applied at high scale to screen germplasm for resistance to $R$. solanacearum. Stable insertion of a lux$C D A B E$ luminescence reporter operon in the $R$. solanacearum genome has facilitated real-time monitoring of bacterial growth in plant hosts and has been used to evaluate potato resistance in plants grown in pots $[20$, 28]. To improve this screening method, we applied the luxCDABE luminescence reporter in our in vitro infection system. To this end, we used the strain GMI1000 (Pps-Lux) carrying the entire Lux operon under the control of the PpsbA chloroplast promoter, which exhibits strong, constitutive expression when introduced into $R$. solanacearum $[20,29]$. As expected, potato plants infected with either GMI1000 or GMI1000 (Ppsba-lux) showed comparable wilting symptoms (Fig. 9a) and bacterial counts (Fig. 9b) in potato at $5 \mathrm{dpi}$. In addition, light detection with a luminometer showed a strong luminescence signal only in plants infected with GMI1000 (Ppsba-Lux) (Fig. 9c). These data corroborate that insertion of the PpsbA::luxCDABE in the $R$. solanacearum genome affect neither its colonization ability nor its capacity to cause disease symptoms. The application of a luminescence reporter increases the efficiency of our hydroponic potato infection system for evaluation of potato germplasm resistance to bacterial wilt.

\section{Discussion}

The interaction between $R$. solanacearum and its plant hosts has been established as a model system to study plant resistance to soil-borne bacterial phytopathogens for more than two decades [10,24]. Soil-drench and/or stem penetration inoculations are mostly used to investigate bacterial wilt disease progress on tomato, eggplant, potato, the model plants Medicago truncatula and Arabidopsis [10-13, 20,30]. Using any of these two infection methods requires a large amount of time and space, with the ensuing high costs. Moreover, the growth in soil prevents the investigation of early root responses to the pathogen $[17,20]$. To overcome these problems, we set up here an in vitro inoculation assay on potato. The in vitro potato inoculations have previously been used to quantify blackleg disease on shoots, showing results comparable to greenhouse assays [31]. Chen and colleagues successfully identified three SSR alleles related to bacterial wilt resistance from Solanum tuberosum $+S$. chacoense somatic hybrids through in vitro inoculation of potato plants grown in solid medium [32]. However, their infection protocol was not described explicitly. Here, we thoroughly described a quick, accurate and space-saving potato infection system to monitor $R$. solanacearum using plants grown under hydroponic in vitro conditions. In our system, four potato plants were directly propagated into a container and infected two weeks later with a $R$. solanacearum solution. Compared to soil drench inoculation [20] our method saves two-weeks. In our assay, $75 \%$ of plants were completely wilted at $2-3$ days after the first wilting symptoms were recorded (Figs. 2a, $4 a, 5 a$ and $8 a$ ), showing that this assay is very stable and repetitive. Our recently established in vitro infection system for Arabidopsis grown on agar plates has shown that $R$. solanacearum infection changes the root architecture $[16,17,33]$. This phenomenon could not be observed and investigated by means of a traditional soil-drench or stem penetration inoculations. Thus, our assay provides the possibility to investigate early potato responses to $R$. solanacearum.

The HrpG and HrpB transcriptional regulators control the virulence of $R$. solanacearum through modulating the expression of the genes encoding the type three secretion system and its related effectors [25, 34]. The deletion of hrp $G$ and $h r p B$ abolished wilt symptom occurrence and restrained the pathogen proliferation in potato plants (Fig. 6), which is consistent with the mutant strains loss ability to infect on the tomato and Arabidopsis [14, 17]. However, while the $\Delta h r p G$ deletion mutant grew more than $\triangle h r p B$ in tomato stems [14], these two strains grew 

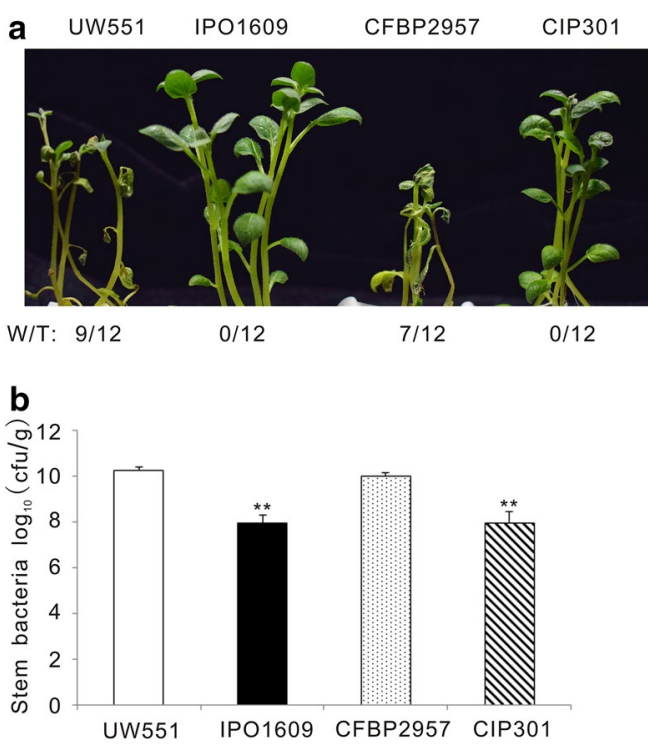

Fig. 7 R. solanacearum strains showed differential virulence in in vitro potato infection system. a Representative picture of inoculated plants at $4 \mathrm{dpi}$. "W/T" indicates the number of wilting plants with respect to the total of infected plants. $\mathbf{b}$ The bacterial content in potato stems measured at $4 \mathrm{dpi}$. This experiment was repeated three times with similar results. ${ }^{* *} P<0.001$ (Student's $t$ test) comparing with UW551 strain

to similar levels in potato. This could be a host speciesdependent phenomenon. In line with this hypothesis, the capacity of the $\triangle h r p B$ strain to colonize Arabidopsis seems to be stronger than that of the $\Delta h r p G$ strain [17].

$R$. solanacearum strains UW551 and IPO1609 belong to race 3 biovar 2, which causes potato brown rot at cool temperatures [26]. In our potato infection assay UW551 was much more aggressive than IPO1609, causing stronger wilting symptoms and increased bacterial growth. In accordance with this, it has been reported that the pathogenicity of IPO1609 was strongly attenuated on tomato and potato relative to UW551 when using a soildrench inoculation method, due to a major deletion present in its genome [26]. We also found that strain CIP301, isolated from potato, did not display strong virulence on potato. Therefore we speculate it may be a hypoaggressive strain similar to IPO1609. CFBP2957 from tomato exhibited hypervirulence on potato in our assay. This is not surprising, as it has been known for long that host range in nature does not always correlate with aggressivity on different hosts under laboratory conditions. For instance, UW551, a potato strain, has been reported to cause strong bacterial wilt on tomato [26]. All these data indicate that this in vitro infection assay is suitable for evaluating the pathogenicity of $R$. solanacearum strains on potato as accurately as when soil drench inoculation is used. In addition, our hydroponic infection also provides the possibility to directly investigate the interaction between potato root and other soil-borne pathogens.

Three wild type potato lines were identified with higher bacterial wilt resistance among 32 tested candidate lines. This indicates that the in vitro infection system established here can be effectively applied to high-throughput screening for bacterial wilt resistance in potato germplasm. Wilting symptoms are the simplest way to evaluate plant resistance to bacterial wilt. However, symptom recording is time consuming and latent symptomless infections that can cause havoc when environmental conditions change $[20,35,36]$ escape detection. Thus, latent infection limits the application of leaf wilting to evaluate potato resistance to the pathogen. To overcome this problem, we employed a luminescent reporter strain [20, 29] in our infection system to be able to quantify bacteria inside the plant, which may not have caused symptoms. Luminescence intensity was positively correlated with bacteria colonization in the infected plant stem (Fig. 9). However, unlike our previous studies [20], bacterial colonization in the infected plant could not be visualized in this work using a light imaging system (ChemiDoc ${ }^{\mathrm{TM}}$ XRST). One reason for this could that the luminescent GMI1000 strain originally isolated from tomato is less aggressive than the luminescent UY031 strain on potato that we used in previous reports [37, 38]. In addition, it is possible that the bacterial concentrations carried by the younger plants used here are below the detection limits of the light imaging system. In any case, we could effectively quantify the luminescent bacteria with a luminometer. Compared with colony counting after dilution plating, detection of bacterial luminescence from crushed stems using a 96-well plate luminometer is a faster, more reliable procedure.

\section{Conclusion}

In this study, a hydroponic potato infection assay in vitro has successfully been established for $R$. solanacearum. This assay is less time-consuming, low-cost, accurate and easier to handle comparing with the previously described and widely used infection assays. We demonstrated that it can also be applicable for large-scale screening of potato germplasm for resistance to brown rot disease, which will speed up and increase the efficiency of breeding resistance into potato cultivars.

\section{Materials and methods}

\section{Plants and strains}

Two centimeter shoot explants from Solanum tuberosum L. Désirée; B and N from S. tuberosum subsp. Andigenum; M, O, P from S. Raphanifolium; L from S. Pinnatisectum) were cut and inserted into paper holders which were immersed in $35 \mathrm{ml}$ MS liquid medium (4.405 g/l 

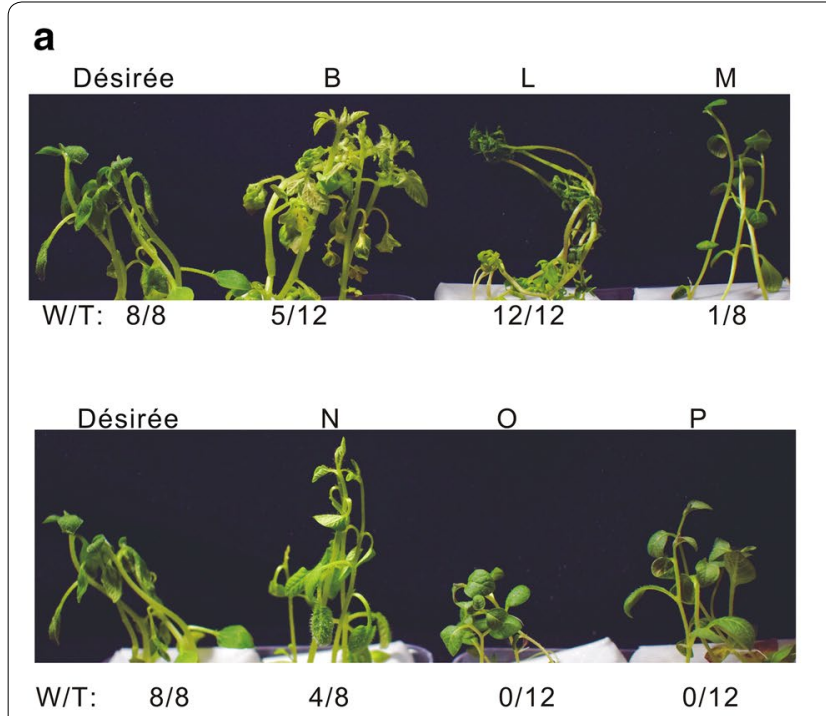

C

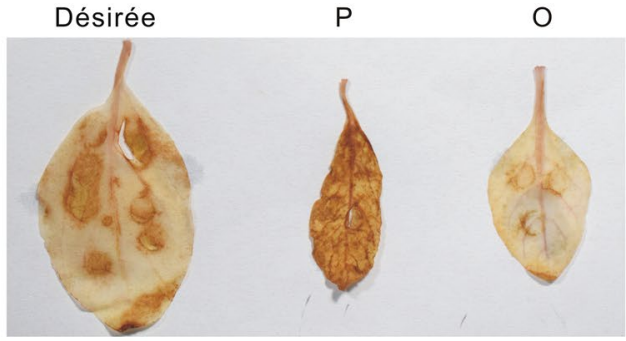

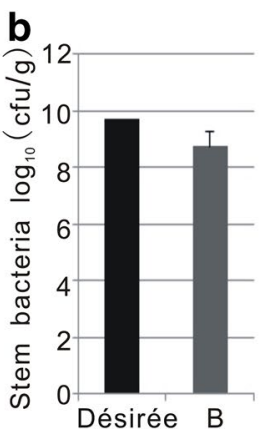
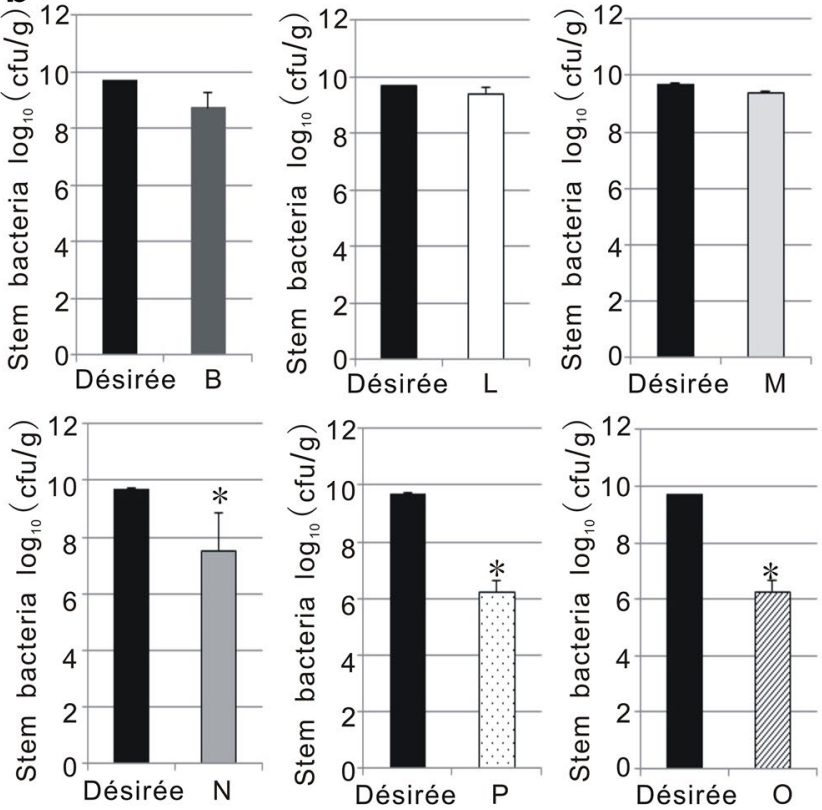

Désirée

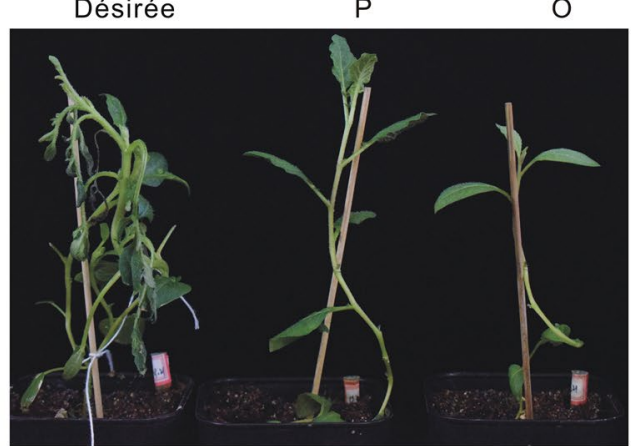

Fig. 8 Potato varieties exhibited differential resistance to GMI1000 in the in vitro infection system. a Representative image of inoculated plants taken at $4 \mathrm{dpi}$. "W/T" represents the number of wilted plants over the total of infected plants. Tested varieties include: Solanum tuberosum L. Désirée; S. tuberosum subsp. andigenum (varieties B and N); S. raphanifolium (varieties $\mathrm{M}, \mathrm{O}, \mathrm{P}$ ) and S. pinnatisectum (variety L). b Bacterial content in potato stems measured at 4 dpi. ${ }^{*}$ < 0.01 (Student's $t$ test) with respect to Désirée. c ROS production in the infiltrated leaves of potatos measured at $3 \mathrm{dpi}$. Left: DAB staining; Right: representative image of the plants for DAB staining assay taken at $6 \mathrm{dpi}$. These experiments were repeated at least twice with similar results

MS salt including vitamins, $20 \mathrm{~g} / \mathrm{l}$ sucrose, $\mathrm{pH}$ 5.8). Four plants were grown in each glass jar (diameter $=8 \mathrm{~cm}$ ), containing $35 \mathrm{ml}$ of MS- solution (or tap water after infection when indicated). Plants were grown in a chamber under long day conditions ( $16 \mathrm{~h}$ light, $8 \mathrm{~h}$ dark), $23^{\circ} \mathrm{C}$, $75 \%$ humidity and 10,000 lx light intensity conditions.

To prepare bacterial inocula, 2-3 single $R$. solanacearum colonies (strains GMI1000, UW551, IPO1609, CFBP2957 or CIP301) were transferred into $10 \mathrm{ml}$ liquid B medium ( $10 \mathrm{~g} / \mathrm{l}$ peptone, $1 \mathrm{~g} / \mathrm{l}$ yeast extract and $1 \mathrm{~g} / \mathrm{l}$ casamino acid) and incubated overnight at $28^{\circ} \mathrm{C}$ in a shaker.

\section{In vitro potato infection assay}

Overnight $R$. solanacearum cultures were collected by centrifugation (4000 rpm, $5 \mathrm{~min}$ ), washed once with MS-/tap water, diluted with MS-/tap water and adjusted to $\mathrm{OD}_{600}=0.01$. Then the bacterial suspensions were distributed into jars, using $35 \mathrm{ml}$ per jar for infection.

Roots of 2-week-old potato plants were cut with scissors $2 \mathrm{~cm}$ below the stem and put into the bacterial suspension for inoculation. Inoculated potato plants were kept in the growth chamber under long day conditions (16 h light, $8 \mathrm{~h}$ dark), $25^{\circ} \mathrm{C}$ and 10,000 lx light and 

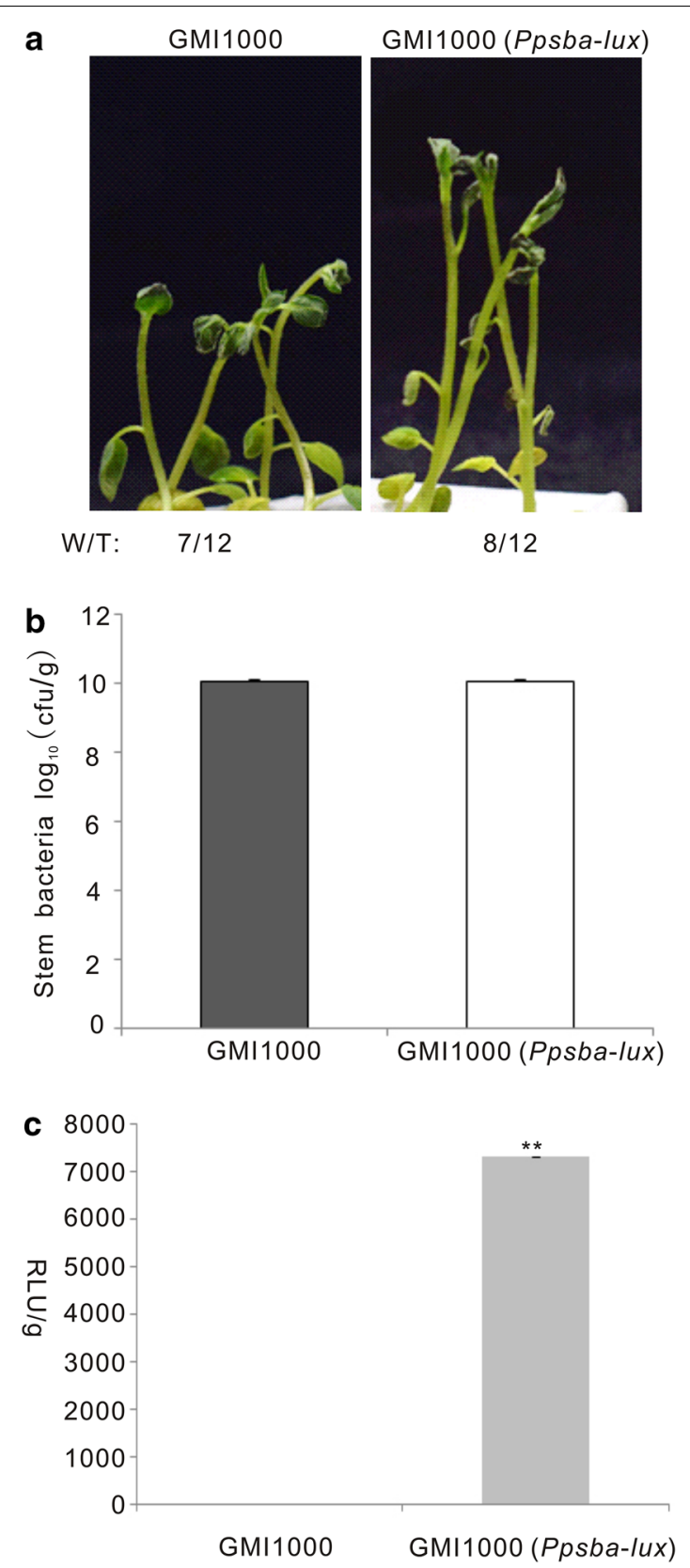

Fig. 9 The growth of luminescent $R$. solanacearum was easily detected in plants. a Representative picture of infected potato plants taken at 5 dpi. b Bacterial content in the stem counted at 5 dpi. c Luminescence of $R$. solanacearum (Ppsba-lux) detected with a 96-well plate reader using the luminometer mode. This experiment was performed at least twice with similar results. ${ }^{* *} P<0.001$ (Student's $t$ test) with respect to GMI1000

$70 \%$ humidity. At $2 \mathrm{dpi}$, the lid of the jar containing the infected plants was loosened to allow air exchange. Wilting symptoms on the infected plants were recorded by taking digital images at the indicated times.

\section{DAB staining assay}

Plant leaves were directly infiltrated with $R$. solanacearum solution at $\mathrm{OD}=0.001$. Infiltrated leaves were detached at the indicated time and immediately immersed into $1 \mathrm{mg} / \mathrm{ml} \mathrm{DAB}$ solution for overnight in the dark. Then the leaves were de-stained with absolute ethanol and boiled for $10 \mathrm{~min}$ and photographed.

\section{Bacteria counting and bacteria luminescence quantification}

The aerial part of the infected plants was harvested $1 \mathrm{~cm}$ above the level of the liquid in the jars and weighed, then homogenized with pestle and mortar. Two $\mathrm{ml}$ double distilled water $\left(\mathrm{ddH}_{2} \mathrm{O}\right)$ was added and mixed with the plant material and the homogenates were serially diluted in water and plated on solid B medium. Plates were kept in the $28{ }^{\circ} \mathrm{C}$ incubator for $48 \mathrm{~h}$ and bacterial colonies were counted. The bacterial contents in the stem $(\mathrm{cfu} / \mathrm{fresh}$ weight of aerial part of the infected plants) was used to evaluate bacterial virulence or plant resistance.

For luminescence measurement assays, the homogenates from the aerial tissues of infected plants were transferred to a 96-well plate (Nunclone) and the luminescence emitted from the pathogen was measured and quantified with a plate reader infinite 200 Pro (Tecan). Luminescence readings were normalized to the fresh weight of each sample and presented as RLU (relative luminescence units) per gram of fresh tissue.

\section{Acknowledgements}

We are grateful for helps from Prof. Changgen Xie (Northwest A \& F University) and the crop biology innovation center of college of agronomy (Northwest A \& F University).

\section{Authors' contributions}

$\mathrm{CZ}, \mathrm{QC}$ and $\mathrm{HL}$ designed the experiments. $\mathrm{HW}, \mathrm{JH}, \mathrm{YL}, \mathrm{MZ}, \mathrm{NQ}$ and $\mathrm{RZ}$ carried out the experiments. YH and DW prepared materials for in vitro system. YC, CZ and HL analyzed the data. CZ, NSC, MV and HL wrote the paper. All authors read and approved the final manuscript.

\section{Funding}

This study was supported by the National Natural Science Foundation of China (No. 31601703), the Start-up Funds of Northwest A\&F University (Z111021601), the Fundamental Research Fund for the Central Universities of China (Z109021706) and External Science and Technology Cooperation Program of Ningxia Academy of Agriculture and Forestry Sciences (DW-X2018012). N.S.C. and M.V. work was funded by projects AGL2016-78002-R. (Spanish Ministry of Economy and Competitiveness) and financial support from the "Severo Ochoa Programme for Centres of Excellence in R\&D" (SEV-2015-0533) and the CERCA Programme from the Catalan Government (Generalitat de Catalunya).

\section{Availability of data and material}

All data generated or analysed during the this study are included in this published article.

\section{Ethics approval and consent to participate} Not applicable. 


\section{Consent for publication}

Not applicable.

\section{Competing interests}

The authors declare that they have no competing interests.

\begin{abstract}
Author details
${ }^{1}$ College of Agronomy and State Key Laboratory of Crop Stress Biology for Arid Areas, Northwest A\&F University, Yangling 712100, Shaanxi, China. ${ }^{2}$ Centre for Research in Agricultural Genomics (CRAG), CSIC-IRTA-UAB-UB, Campus UAB, Bellaterra, 08193 Barcelona, Catalonia, Spain. ${ }^{3}$ Department of Genetics, University of Barcelona, 08028 Barcelona, Catalonia, Spain. ${ }^{4}$ State Key Laboratory of Crop Stress Biology for Arid Areas, College of Food Science and Engineering, Northwest A \& F University, Yangling 712100, Shaanxi, China.
\end{abstract}

Received: 1 August 2019 Accepted: 18 November 2019 Published online: 30 November 2019

\section{References}

1. Mansfield J, Genin S, Magori S, Citovsky V, Sriariyanum M, Ronald P, Dow M, Verdier V, Beer SV, Machado MA, et al. Top 10 plant pathogenic bacteria in molecular plant pathology. Mol Plant Pathol. 2012;13:614-29.

2. Genin S. Molecular traits controlling host range and adaptation to plants in Ralstonia solanacearum. New Phytol. 2010;187:920-8.

3. Genin S, Denny TP. Pathogenomics of the Ralstonia solanacearum species complex. Ann Rev Phytopathol. 2012;50:67-89.

4. van Overbeek LS, Bergervoet JH, Jacobs FH, van Elsas JD. The low-temperature-induced viable-but-nonculturable state affects the virulence of Ralstonia solanacearum Biovar 2. Phytopathology. 2004;94:463-9.

5. Guidot A, Prior P, Schoenfeld J, Carrere S, Genin S, Boucher C. Genomic structure and phylogeny of the plant pathogen Ralstonia solanacearum inferred from gene distribution analysis. J Bacteriol. 2007;189:377-87.

6. Safni I, Cleenwerck I, DeVos P, Fegan M, Sly L, Kappler U. Polyphasic taxonomic revision of the Ralstonia solanacearum species complex: proposal to emend the descriptions of Ralstonia solanacearum and Ralstonia syzygii and reclassify current $R$. syzygii strains as Ralstonia syzygii subsp. syzygii subsp. nov., R. solanacearum phylotype IV strains as Ralstonia syzygii subsp. indonesiensis subsp. nov., banana blood disease bacterium strains as Ralstonia syzygii subsp. celebesensis subsp. nov. and R. solanacearum phylotype I and III strains as Ralstonia pseudosolanacearum sp. nov. Int J Syst Evol Microbiol. 2014;64:3087-103.

7. Wicker E, Grassart L, Coranson-Beaudu R, Mian D, Guilbaud C, Fegan M, Prior P. Ralstonia solanacearum strains from Martinique (French West Indies) exhibiting a new pathogenic potential. Appl Environ Microbiol. 2007;73:6790-801.

8. Hardigan MA, Laimbeer FPE, Newton L, Crisovan E, Hamilton JP, Vaillancourt B, Wiegert-Rininger K, Wood JC, Douches DS, Farre EM, et al. Genome diversity of tuber-bearing Solanum uncovers complex evolutionary history and targets of domestication in the cultivated potato. Proc Natl Acad Sci USA. 2017;114:E9999-E10008.

9. Li Y, Colleoni C, Zhang J, Liang Q, Hu Y, Ruess H, Simon R, Liu Y, Liu H, Yu $\mathrm{G}$, et al. Genomic analyses yield markers for identifying agronomically important genes in potato. Mol Plant. 2018;11:473-84.

10. Deslandes L, Pileur F, Liaubet L, Camut S, Can C, Williams K, Holub E, Beynon J, Arlat M, Marco Y. Genetic characterization of RRS1, a recessive locus in Arabidopsis thaliana that confers resistance to the bacterial soilborne pathogen Ralstonia solanacearum. MPMI. 1998;11:659-67.

11. Jacobs JM, Milling A, Mitra RM, Hogan CS, Ailloud F, Prior P, Allen C. Ralstonia solanacearum requires PopS, an ancient AvrE-family effector, for virulence and to overcome salicylic acid-mediated defenses during tomato pathogenesis. mBio. 2013;4:e00875-e913.

12. Lebeau A, Gouy M, Daunay MC, Wicker E, Chiroleu F, Prior P, Frary A, Dintinger J. Genetic mapping of a major dominant gene for resistance to Ralstonia solanacearum in eggplant. TAG. 2013;126:143-58.

13. Remigi P, Anisimova M, Guidot A, Genin S, Peeters N. Functional diversification of the GALA type III effector family contributes to Ralstonia solanacearum adaptation on different plant hosts. New Phytol. 2011;192:976-87.
14. Vasse J, Genin S, Frey P, Boucher C, Brito B. The hrpB and hrpG regulatory genes of Ralstonia solanacearum are required for different stages of the tomato root infection process. MPMI. 2000;13:259-67.

15. Singh N, Phukan T, Sharma PL, Kabyashree K, Barman A, Kumar R, Sonti RV, Genin S, Ray SK. An innovative root inoculation method to study Ralstonia solanacearum pathogenicity in tomato seedlings. Phytopathology. 2018;108:436-42.

16. Digonnet C, Martinez Y, Denance N, Chasseray M, Dabos P, Ranocha P, Marco Y, Jauneau A, Goffner D. Deciphering the route of Ralstonia solanacearum colonization in Arabidopsis thaliana roots during a compatible interaction: focus at the plant cell wall. Planta. 2012;236:1419-31.

17. Lu H, Lema AS, Planas-Marques M, Alonso-Diaz A, Valls M, Coll NS. Type III secretion-dependent and -independent phenotypes caused by Ralstonia solanacearum in Arabidopsis Roots. MPMI. 2018;31:175-84.

18. Zolobowska L, Van Gijsegem F. Induction of lateral root structure formation on petunia roots: a novel effect of GMI1000 Ralstonia solanacearum infection impaired in Hrp mutants. MPMI. 2006;19:597-606.

19. Vailleau F, Sartorel E, Jardinaud MF, Chardon F, Genin S, Huguet T, Gentzbittel L, Petitprez M. Characterization of the interaction between the bacterial wilt pathogen Ralstonia solanacearum and the model legume plant Medicago truncatula. MPMI. 2007;20:159-67.

20. Cruz AP, Ferreira V, Pianzzola MJ, Siri MI, Coll NS, Valls M. A novel, sensitive method to evaluate potato germplasm for bacterial wilt resistance using a luminescent Ralstonia solanacearum reporter strain. MPMI. 2014:27:277-85.

21. Ferreira V, Pianzzola MJ, Vilaro FL, Galvan GA, Tondo ML, Rodriguez MV, Orellano EG, Valls M, Siri MI. Interspecific potato breeding lines display differential colonization patterns and induced defense responses after Ralstonia solanacearum infection. Front Plant Sci. 2017:8:1424.

22. Hirsch J, Deslandes L, Feng DX, Balague C, Marco Y. Delayed symptom development in ein2-1, an Arabidopsis ethylene-insensitive mutant, in response to bacterial wilt caused by Ralstonia solanacearum. Phytopathology. 2002:92:1142-8.

23. Brito B, Marenda M, Barberis P, Boucher C, Genin S. prhJ and hrpG, two new components of the plant signal-dependent regulatory cascade controlled by PrhA in Ralstonia solanacearum. Mol Microbiol. 1999;31:237-51.

24. Genin S, Gough CL, Zischek C, Boucher CA. Evidence that the hrpB gene encodes a positive regulator of pathogenicity genes from Pseudomonas solanacearum. Mol Microbiol. 1992;6:3065-76.

25. Valls M, Genin S, Boucher C. Integrated regulation of the type III secretion system and other virulence determinants in Ralstonia solanacearum. PLoS Pathog. 2006;2:e82

26. Gonzalez A, Plener L, Restrepo S, Boucher C, Genin S. Detection and functional characterization of a large genomic deletion resulting in decreased pathogenicity in Ralstonia solanacearum race 3 biovar 2 strains. Environ Microbiol. 2011;13:3172-85.

27. Marcec MJ, Gilory S, Poovaiah BW, Tanaka K. Mutual interplay of $\mathrm{Ca}^{2+}$ and ROS signalling in plant immune response. Plant Sci. 2019;283:343-54.

28. Monteiro F, Genin S, van Dijk I, Valls M. A luminescent reporter evidences active expression of Ralstonia solanacearum type III secretion system genes throughout plant infection. Microbiology. 2012;158:2107-16.

29. Puigvert M, Sole M, Lopez-Garcia B, Coll NS, Beattie KD, Davis RA, Elofsson $M$, Valls M. Type III secretion inhibitors for the management of bacterial plant diseases. Mol Plant Pathol. 2019;20:20-322.

30. Wang K, Remigi P, Anisimova M, Lonjon F, Kars I, Kajava A, Li CH, Cheng CP, Vailleau F, Genin S, et al. Functional assignment to positively selected sites in the core type III effector RipG7 from Ralstonia solanacearum. Mol Plant Pathol. 2016;17:553-64.

31. Burra DD, Muhlenbock P, Andreasson E. Salicylic and jasmonic acid pathways are necessary for defence against Dickeya solani as revealed by a novel method for Blackleg disease screening of in vitro grown potato. Plant Biol (Stuttg). 2015;17:1030-8

32. Chen L, Guo X, Xie C, He L, Cai X, Tian L, Song B, Liu J. Nuclear and cytoplasmic genome components of Solanum tuberosum + S. chacoense somatic hybrids and three SSR alleles related to bacterial wilt resistance. TAG. 2013;126:1861-72.

33. Zhao C, Wang H, Lu Y, Hu J, Qu L, Li Z, Wang D, He Y, Valls M, Coll NS, et al. Deep sequencing reveals early reprogramming of arabidopsis root transcriptomes upon ralstonia solanacearum infection. MPMI. 2019;10:180268. 
34. Brito B, Aldon D, Barberis P, Boucher C, Genin S. A signal transfer system through three compartments transduces the plant cell contactdependent signal controlling Ralstonia solanacearum hrp genes. MPMI. 2002:15:109-19.

35. French ER, De Lindo L. Resistance to Pseudomonas solanacearum in potato specificity and temperature sensitivity. Phytopathology. 1982;72:1408-12.

36. Tung PX, Rasco ET, Vander Zaag P, Schmiediche P. Resistance to Pseudomonas solanacearum in the potato: II. Aspects of host-pathogen-envrioment interaction. Euphytica. 1990;45:211-5.

37. Salanoubat M, Genin S, Artiguenave F, Gouzy J, Mangenot S, Arlat M, Billault A, Brottier P, Camus JC, Cattolico L, et al. Genome sequence of the plant pathogen Ralstonia solanacearum. Nature. 2002;415:497-502.
38. Siri MI, Sanabria A, Pianzzola MJ. Genetic diversity and aggressiveness of Ralstonia solanacearum strains causing bacterial wilt of potato in uruguay. Plant Dis. 2011;95:1292-301.

\section{Publisher's Note}

Springer Nature remains neutral with regard to jurisdictional claims in published maps and institutional affiliations.
Ready to submit your research? Choose BMC and benefit from:

- fast, convenient online submission

- thorough peer review by experienced researchers in your field

- rapid publication on acceptance

- support for research data, including large and complex data types

- gold Open Access which fosters wider collaboration and increased citations

- maximum visibility for your research: over 100M website views per year

At BMC, research is always in progress.

Learn more biomedcentral.com/submissions 